\title{
Configurações
}

Revista de sociologia

\section{Cuidadores familiares idosos: Uma nova realidade, um novo desafio para as políticas sociais}

Elderly family caregivers: a new reality, a new challenge for social policies

Aidants familiaux âgés : une nouvelle réalité, un nouveau défi pour les politiques sociales

Fátima Barbosa e Alice Delerue Matos

\section{OpenEdition}

Journals

Edição electrónica

URL: http://journals.openedition.org/configuracoes/491

DOI: 10.4000/configuracoes.491

ISSN: 2182-7419

\section{Editora}

Centro de Investigação em Ciências Sociais

\section{Edição impressa}

Data de publição: 1 Janeiro 2008

Paginação: 127-139

ISSN: 1646-5075

\section{Refêrencia eletrónica}

Fátima Barbosa e Alice Delerue Matos, « Cuidadores familiares idosos: Uma nova realidade, um novo desafio para as políticas sociais », Configurações [Online], 4 | 2008, posto online no dia 12 fevereiro 2012, consultado o 03 maio 2019. URL : http://journals.openedition.org/configuracoes/491 ; DOI : $10.4000 /$ configuracoes.491

Este documento foi criado de forma automática no dia 3 Maio 2019 


\title{
Cuidadores familiares idosos: Uma nova realidade, um novo desafio para as políticas sociais
}

\author{
Elderly family caregivers: a new reality, a new challenge for social policies \\ Aidants familiaux âgés : une nouvelle réalité, un nouveau défi pour les politiques \\ sociales
}

Fátima Barbosa e Alice Delerue Matos

\section{Introdução}

1 O envelhecimento populacional ${ }^{1}$ gerou diversos riscos (incapacidades, isola- mento, solidão e exclusão social dos idosos) que a sociedade não estava preparada para enfrentar (Quaresma, Fernandes, Calado e Pereira 2004). Os idosos vivem cada vez mais tempo, mas fazem-no frequentemente acompanhados de patologias, algumas delas causadoras de dependência.

2 Uma das principais funções da família é a de solidariedade intergeracional. Contudo, a família vê-se muitas vezes impedida de a exercer, total ou parcialmente, devido a um conjunto de mudanças ocorridas, nas últimas décadas, na sua estrutura e dinâmica. Entre outros fatores, a entrada da mulher para o mercado de trabalho veio dificultar ou impossibilitar o exercício do papel que a família assumia enquanto cuidadora dos idosos dependentes. Assiste-se então à transferência desta responsabilidade ou à sua partilha com outrem. $\mathrm{O}$ apoio aos idosos deixa de ser exclusivo da família, passando a ser repartido com as instituições públicas e privadas de solidariedade social, prestadores de serviços remunerados ou em regime de voluntariado e vizinhos.

3 Na família, o acto ou a tarefa de zelar pelo bem-estar de alguém (Vieira 1996), ou seja, o cuidar de outrem, é assumido frequentemente pelos próprios cônjuges, que, inúmeras vezes, deveriam usufruir também eles de assistência. 
O aumento do número de casos de idosos a gerirem os cuidados a idosos dependentes levou-nos a tentar determinar os riscos decorrentes desta situação e as soluções que melhor os permitem minimizar. Assim, este trabalho visa analisar a gestão dos cuidados a idosos dependentes que se encontram em contexto domiciliar, a cargo de cuidadores familiares idosos, e tem os seguintes objectivos principais:

- compreender como é que os cuidadores familiares idosos gerem a prestação de cuidados aos idosos dependentes;

- identificar as diferentes soluções de apoio (formais e informais) que os cuida- dores familiares idosos utilizam, no seu dia-a-dia, para cuidar dos idosos dependentes;

- explicitar as necessidades dos cuidadores familiares idosos tendo em conta as diferentes soluções de apoio adoptadas.

\section{Metodologia e caracterização da amostra}

Entre Janeiro e Março de 2008, realizámos dezassete entrevistas semi-estruturadas a idosos gestores de cuidados a outros idosos que usufruem do Serviço de Apoio Domiciliário da Santa Casa da Misericórdia de Barcelos, do Centro Social de Silveiros (pertencente à Santa Casa da Misericórdia de Barcelos) e da Casa do Povo de Alvito S. Pedro. Estas entrevistas foram precedidas da avaliação sumária do grau de dependência do idoso a cargo com base na escala MDA - Mini Dependance Assessment (Benhamou, s.d.), que permite calcular a dependência do indivíduo nas actividades da vida diária e "estimar o impacto da deterioração cognitiva na actividade quotidiana da pessoa" (Sequeira 2007), com base em doze critérios que abrangem quatro tipos de actividades: corporais, locomotoras, sensoriais e mentais.

Dos dezassete entrevistados, dezasseis são cônjuges do idoso que recebe cuidados. A sua distribuição por sexos é equitativa: oito prestadores são do sexo feminino e nove do sexo masculino. Em geral, o cuidador familiar directo é um indivíduo do sexo feminino, mas, nas famílias com ausência de redes de suporte descendente, os homens assumem o papel de cuidadores (Lesemann e Martin 1993).

7 A média de idades dos cuidadores familiares é de 76 anos para o sexo feminino e de 75 anos para o sexo masculino.

Residem em meio urbano dez cuidadores e em meio rural sete outros. Todos têm um nível de instrução muito baixo que, apenas num caso, ultrapassa quatro anos de escolaridade.

Dos dezassete idosos dependentes, nove eram do sexo feminino e oito do sexo masculino com uma idade média de 75 anos. De acordo com a escala MDA referida anteriormente, o grau de dependência destes idosos era o seguinte:

- grau de dependência ligeiro: três idosos do sexo feminino;

- grau de dependência moderado: seis idosos, sendo três do sexo masculino e três do sexo feminino;

- grau de dependência severo: três idosos, sendo dois do sexo masculino e um do sexo feminino;

- grau de dependência muito severo: cinco idosos, sendo três do sexo masculino e dois do sexo feminino.

10 Na amostra, a idade e o sexo dos idosos que recebem cuidados não constituem factores explicativos da dependência, uma vez que existem diferentes idades em todos os graus de 
dependência e apenas a prevalência do sexo feminino nos idosos com um grau de dependência ligeiro.

\section{O papel dos cuidadores familiares idosos na gestão dos cuidados aos idosos dependentes}

11 Perante a indisponibilidade dos filhos adultos, ou melhor, das filhas e noras, para cuidarem dos idosos dependentes, os cônjuges assumem-se, frequentemente, como principais responsáveis pela gestão destas tarefas. Cuidados de higiene e conforto, alimentação, saúde e supervisão são entregues a idosos que possuem fragilidades e problemas de saúde, não tão incapacitantes quanto os dos idosos dependentes mas que podem desencadear situações prejudiciais para estes últimos e também para os cuidadores sujeitos à elevada sobrecarga física, psicológica e social que caracteriza os cuidados a outrem.

Quando os cuidadores familiares idosos possuem retaguarda familiar, a sobre- carga e os riscos tendem a ser divididos com a restante família. Contudo, existem cuidadores familiares idosos que não possuem esta retaguarda familiar e asseguram sós o apoio a um idoso dependente, estando mais expostos a todos os riscos inerentes à prestação de cuidados.

13 Sabendo que todos os cuidadores participantes nesta pesquisa beneficiavam do Serviço de Apoio Domiciliário, quisemos apurar a que outro tipo de apoios (formais e informais) recorriam de forma regular. Verificamos que fazem apelo a diferentes tipos de prestadores, sendo os filhos adultos, os vizinhos e as empregadas domésticas os mais frequentes.

Pretendendo comparar a situação dos cuidadores familiares idosos que possuem apoio da família e a situação dos que o não têm, considerámos dois tipos de soluções na prestação de cuidados aos idosos dependentes à responsabilidade de outros idosos:

\section{Solução A}

15 Os cuidadores idosos apoiam-se nos filhos adultos e no Serviço de Apoio Domiciliário e, nalguns casos, nos serviços de uma empregada. Esta solução subdivide-se em:

- Solução A1, em que os filhos co-residem com os cuidadores;

- Solução A2, em que os filhos que apoiam o cuidador principal não residem com ele.

\section{Solução B}

Os cuidadores idosos apoiam-se no Serviço de Apoio Domiciliário, nos vizinhos e, nalguns casos, numa empregada.

17 Tendo em conta as características dos cuidadores e dos idosos dependentes que se inserem em cada um dos dois tipos de soluções de cuidados a outrem que acabámos de descrever, verificámos que o sexo dos cuidadores, o seu nível de escolaridade e o local de residência (urbano/rural) não condicionam o tipo de solução adoptada. Por outro lado, o grau de dependência dos idosos a cargo não determina o tipo de apoio accionado, pois existem diferentes graus de dependência em cada uma das soluções de cuidados referidas. O que parece condicionar os apoios de que usufruem os cuidadores familiares é a sua capacidade económica, as relações familiares e ainda as relações de vizinhança. Com 
efeito, mais capacidade económica significa mais possibilidades de acesso a serviços de apoio, relações familiares positivas ao longo da vida originam apoios familiares mais intensos e boas relações de vizinhança criam redes de entreajuda entre os vizinhos.

Constata-se também que, depois do apoio dos filhos e do Serviço de Apoio Domiciliário, os cuidadores idosos do sexo masculino recorrem mais à ajuda dos vizinhos, enquanto os cuidadores do sexo feminino se apoiam numa empregada. A justificação poderá residir no facto de os homens não terem o hábito de executar tarefas de tipo instrumental dirigindo-se aos vizinhos, na ausência de retaguarda familiar: "Esta minha vizinha da frente é que vinha aqui para eu a colocar na casa de banho e vinham aqui todas as noites ajudar a deitar porque eu sozinho não podia." (Entrevista n.ำ).

As mulheres socorrem-se das empregadas que lhes executam as tarefas de casa (limpeza da habitação, tratamento de roupa e compras) e as auxiliam na prestação de cuidados directos ao idoso dependente (Entrevistas n.os 2, 3, 4, 5 e 7).

21 Há que referir ainda que os cuidadores de ambos os sexos não delegam nos vizinhos nem nas empregadas as tarefas relacionadas com a saúde, a higiene e o conforto dos idosos dependentes. Assim, a administração da medicação é geralmente uma tarefa da responsabilidade do cuidador, a articulação com médicos e enfermeiros uma tarefa partilhada com os filhos e a higiene e o conforto matinal são realizados exclusivamente pelos cuidadores idosos e pelo Serviço de Apoio Domiciliário e, ao fim-de-semana, apenas pelos cuidadores. Os vizinhos e as empregadas tendem a executar tarefas mais pontuais e de cariz instrumental.

\section{A partilha das responsabilidades dos cuidadores familiares idosos com retaguarda familiar}

22 Como referimos, na solução A, o cuidador familiar idoso, como principal prestador de cuidados, recebe apoio dos filhos, do Serviço de Apoio Domiciliário e, nalguns casos, de uma empregada. Nesta solução encontramos duas realidades distintas: filhos que coresidem com os cuidadores (solução A1) e cuidadores que residem unicamente com o idoso dependente mas que usufruem do apoio frequente dos filhos (solução A2).

Na solução A1 encontramos três indivíduos do sexo masculino e dois do sexo feminino que tratam de idosos com os seguintes graus de dependência: três idosos de grau moderado, um idoso de grau severo e um idoso de grau muito severo.

24 Estes cuidadores possuem um baixo nível de escolaridade (três cuidadores com quatro anos de escolaridade, um cuidador com três anos de escolaridade e um cuidador com nove anos de escolaridade) e vivem em áreas geográficas com características distintas (dois cuidadores vivem em zonas urbanas, um cuidador vive numa zona semi-urbana e dois cuidadores vivem em zonas rurais).

25 Nesta solução de apoio, os filhos estão ausentes durante o período diurno por motivos profissionais, mas assumem um papel activo durante o período nocturno e ao fim-desemana.

Quando existe poder económico, verifica-se a contratação de uma empregada que ajuda o cuidador nas tarefas mais instrumentais, atenuando a sobrecarga inerente aos cuidados prestados ao idoso dependente. Este apoio passa, essencialmente, pelo tratamento da roupa, limpeza da habitação, preparação da alimentação, execução das compras e pela 
ajuda ao cuidador familiar idoso nos serviços directos ao idoso dependente (mudar fraldas, mudar de posição, etc.). Mesmo nas situações em que existe uma empregada, o Serviço de Apoio Domiciliário assegura a higiene matinal e o banho do idoso dependente.

Quando não existe poder económico para contratar uma empregada, os serviços de limpeza da habitação, tratamento da roupa e compras são executados pelos filhos, enquanto o Serviço de Apoio Domiciliário garante os serviços de higiene matinal, banho e alimentação.

A coabitação com os filhos parece não influenciar a escolha da pessoa a quem cabe administrar a medicação. Os cuidadores idosos são responsáveis por esta tarefa, com a excepção de um único caso na nossa amostra, em que os medicamentos são ministrados por um filho. $\mathrm{O}$ mesmo acontece com a responsabilidade de articulação com os médicos e enfermeiros: apenas um cuidador delega essa tarefa nos filhos, os restantes cuidadores são os principais responsáveis pelo contacto com os profissionais de saúde, ainda que apoiados pelos descendentes.

Constata-se que, mesmo existindo empregadas domésticas, estas não executam as tarefas directamente relacionadas com a saúde do idoso dependente. Os filhos também não assumem a responsabilidade deste tipo de tarefas, sendo a maior parte dos cuidados de saúde um encargo dos cuidadores idosos.

Os cuidadores familiares idosos classificados na solução A1 exprimem as seguintes necessidades materiais:

- Acesso a cuidados de saúde: Não vem cá ninguém! Eu nem tenho médico de família, tenho que pedir pelas almas para o médico me passar a guia." (Entrevista n. ${ }^{9}$ );

- Apoio económico: Dinheiro, que está a fazer muita falta, as economias estão-se a acabar... 0 dinheiro vai-se acabando, o meu filho ajuda, mas só em fraldas e em medicação vai muito dinheiro. Depois também tenho a empregada que gostaria de lhe pagar mais, mas não consigo... Cada noite que ela fica cá tenho que lhe pagar e isso tudo fica muito caro..." (Entrevista n. ${ }^{\circ}$ ).

31 Dois cuidadores referem que não necessitam de outros apoios: "Eu estou bem graças a Deus, estamos muito bem..." (Entrevista n. 13);"Ela já tem o carrinho, já temos a assistência do apoio domiciliário, bem que mais havemos de querer? Temos as reformas, é assim, não precisamos de mais nada! (Entrevista n.․ 14).

Na solução A2, o agregado familiar é composto pelo cuidador e idoso dependente, mas os filhos não coabitantes prestam-lhes apoio. Os cuidadores idosos têm a seu cargo idosos com os seguintes graus de dependência: um idoso de grau ligeiro, três idosos de grau moderado, um idoso de grau severo e três idosos de grau muito severo. Possuem baixo nível de escolaridade (dois cuidadores não sabem ler nem escrever, cinco cuidadores têm quatro anos de escolaridade e um cuidador possui três anos de escolaridade) e vivem em áreas geográficas com características distintas, ou seja, quatro cuida- dores vivem na periferia do centro urbano de Barcelos e quatro vivem em zonas rurais.

Neste tipo de solução, ou seja na solução A2, há duas situações distintas. Na primeira, os filhos assumem a responsabilidade de prestar apoio aos pais porque residem próximos deles e, na segunda situação, os filhos vivem distantes, pelo que prestam apoio de acordo com uma escala que engloba a maior parte dos descendentes do idoso dependente. Em geral, este apoio é regular e tem lugar ao final do dia e ao fim-de-semana: "As minhas filhas (três filhas) dividem-se entre elas e todos os dias vem cá uma filha ao final do dia 
ajudar-me a tratar da minha esposa..." (Entrevista n.. 2); "Vem cá sempre um filho à noite..." (Entrevista n.․ 10).

Na solução A2, os cuidadores familiares idosos são responsáveis pela administração da medicação, existindo apenas um caso em que a filha assume esta tarefa: "Agora quem nos tem dado a medicação é a nossa filha, porque agora tenho mais misturas.” (Entrevista n.ำ 1).

Em metade dos casos que se enquadram na solução A2, as refeições são confeccionadas pelos cuidadores idosos, independentemente do sexo destes. Nos outros casos, a alimentação é fornecida pelo Serviço de Apoio Domiciliário.

Relativamente ao serviço de higiene, a maior parte dos cuidadores familiares idosos recorre à ajuda do Serviço de Apoio Domiciliário, havendo apenas dois casos em que a higiene é da responsabilidade dos cuidadores e dos próprios idosos dependentes.

A articulação com os médicos e enfermeiros é feita pelos cuidadores e pelos filhos. Metade dos cuidadores executa esta tarefa de forma independente e outra metade reparte ou delega a mesma nos filhos: "Peço à minha filha e ela vai lá e também me marca as consultas, porque eu tenho um telefone, mas não sei trabalhar com ele." (Entrevista n... 1).

Os filhos fazem a supervisão dos cuidados (à hora do almoço, ao final do dia e ao fim-desemana, em geral) e, na ausência de uma empregada doméstica, executam os serviços de limpeza da habitação, tratamento de roupas e compras: "A gente chama os filhos e eles ajudam, mas mais ao fim-de-semana...” (Entrevista n.. 16).

As principais necessidades dos cuidadores idosos pertencentes à solução A2 situam-se a:

\section{- Nível material}

- Apoio económico: "Gostava de ter mais dinheiro do Estado para assim ter mais coisas..." (Entrevista n.ํ 1).

- Apoio em serviços: "Gostava de ter uma pessoa ao meu lado que me fizesse as coisas, porque eu estou aqui sozinha e sempre era uma ajuda, não era?" (Entrevista n.․ 4); "Gostava de ter um apoio mais alargado, pois libertava-me um pouco a mim e também às minhas filhas. Elas trabalham e não têm tempo. Uma filha vem do Porto para cá cuidar da mãe. Gosto de ter aqui a minha esposa, porque ela aqui tem mais carinho e apoio dos dela. Se houvesse um apoio até mais tarde e com mais profissionais, ela estaria melhor e nós também." (Entrevista n.․ 2); “Queria ter aqui alguém para eu poder dar umas voltas.” (Entrevista n.․11).

\section{- Nível emocional}

- Suporte emocional: “... gostaria de ter mais carinho e apoio dos filhos... Pelo menos de um. Ela mora aqui ao lado e não me ajuda...” (Entrevista n.․ 17); “... força e coragem para estar ao lado dela e a auxiliar o mais possível..." (Entrevista n. $\left.{ }^{\circ} 10\right)$.

40 A maior parte dos cuidadores classificados na solução A (tanto os que coabitam com os filhos - solução A1, como os que não coabitam com os descendentes - solução A2) expressa necessidades materiais: mais acesso a cuidados de saúde e maior capacidade económica.

41 Os cuidadores que coabitam com os filhos são pouco reivindicativos. Ao contrário, os cuidadores familiares idosos que não coabitam com os filhos expressam mais necessidade de apoio emocional e apoio em serviços, nomeadamente, apoio domiciliário permanente. Há que referir ainda que, na solução A, os cuidadores familiares idosos são os principais 
responsáveis pela administração da medicação, repartindo com os filhos a articulação com os médicos de família e enfermeiros. Verificam-se acentuadas diferenças entre os cuidadores que coabitam com os filhos e os cuidadores que não coa- bitam com os filhos. O primeiro grupo de cuidadores familiares idosos apresenta menos necessidades e corre menos riscos, na medida em que tem o apoio dos filhos durante a noite e o fim-desemana. Mesmo assim, estes cuidadores continuam a ser os principais responsáveis pela administração da medicação e pelos cuidados durante o período diurno. 0 segundo grupo de cuidadores apresenta mais necessidades e corre maiores riscos. Este grupo assume sozinho a tarefa de cuidar do idoso 24 horas, possuindo apenas apoio dos filhos ao final do dia e ao fim-de-semana. Estes cuidadores estão mais vulneráveis a riscos e a sobrecargas físicas, psicológicas e sociais.

"Tenho 65 anos, fui emigrante em França e na Alemanha e cá em Portugal trabalhei em várias zonas. Sempre gostei da vida! Reformei-me há sete anos e pensei que ia continuar a ter uma vida bonita, mas enganei-me...há sete anos que não tenho descanso... a minha esposa teve uma trombose e está acamada. Ela berra toda a noite, passo a minha vida lá fora, naquela mesa de pedra, a ver os outros a passar e sempre à espera que chegue o domingo, para ir dar uma volta. Vivo com a minha filha mais nova, os outros filhos estão casados e têm os seus empregos e as suas casas. Quando as empregadas do Apoio Domiciliário chegam, aproveito para ir a Barcelos. Nunca pensei acabar os meus dias assim (choro). Vou morrer em casa, à porta! Dantes um maço de cigarros dava para dois dias, agora... Nunca tomei remédios na minha vida e estou a tomar agora. Nunca sofri de nada e agora estou preso de pés e mãos..."

(Entrevista n. ${ }^{\circ}$ : indivíduo do sexo masculino, 65 anos)

\section{A sobrecarga física e psicológica dos cuidadores familiares idosos sem retaguarda familiar}

Na Solução B os cuidadores familiares idosos não possuem retaguarda familiar, apoiandose no Serviço de Apoio Domiciliário, nos vizinhos e, por vezes, na contratação de uma empregada.

Neste tipo de solução, os cuidadores familiares idosos cuidam de idosos com os seguintes graus de dependência: dois idosos de grau ligeiro, um de grau severo e um de grau muito severo. Estes cuidadores possuem um baixo nível de escolaridade (um cuidador não sabe ler nem escrever e os restantes possuem quatro anos de escolaridade) e vivem em áreas geográficas com características distintas: um cuidador vive em zona urbana, dois residem em zonas semi-urbanas e um cuidador vive em zona rural.

Os cuidadores familiares idosos que se enquadram nesta solução de apoio estão bastante sobrecarregados. Executam mais tarefas que os cuidadores pertencentes à solução A. Não possuindo apoio dos filhos, os cuidadores familiares idosos tentam executar as tarefas relacionadas com a gestão dos cuidados aos idosos dependentes, no limite das suas possibilidades físicas, económicas e relacionais. Como acontecia já na solução A, os cuidadores da Solução B com mais recursos económicos contratam uma empregada que lhes executa as tarefas de limpeza da habitação, tratamento de roupa, compras, etc. Os que não têm possibilidades económicas e não contam com o Serviço de Apoio Domiciliário nestas tarefas vêem-se confrontados com os problemas de falta de limpeza da habitação, ausência de tratamento de roupa e de supervisão. Estes problemas agudizam-se ao fim-desemana, em que os serviços prestados pelo Apoio Domiciliário não são assegurados. 
Os cuidadores da Solução B recebem mais Apoio Domiciliário que os cuidadores com retaguarda familiar em termos de alimentação, higiene e conforto, tratamento de roupa, limpeza da habitação e administração da medicação, mas, frequentemente, este amparo não é suficiente. Não podendo contar com o auxílio da família, estes cuidadores confrontam-se com problemas graves cuja resolução passaria por:

- fornecimento dos serviços de alimentação, higiene e conforto também ao fim- de-semana (apenas o Apoio Domiciliário da Santa Casa da Misericórdia tem lugar de segunda-feira a sábado, mas este serviço não tem capacidade para responder a todas as solicitações nem funciona ao domingo);

- apoio durante um período de tempo mais longo: "Eu queria que viessem à tarde e à noite! Eu não tenho ninguém, necessito de uma ajuda para a noite, estou sozinha!" (Entrevista n.. 12 );

- apoio domiciliário com técnicos de saúde (enfermeiros, médicos, terapeutas, psicólogos...) capazes de melhorar a qualidade de vida do idoso dependente e do cuidador familiar idoso.

De referir que, apenas num caso, o cuidador familiar idoso não é o principal responsável pela administração da medicação, delegando esta tarefa nas funcionárias do Serviço de Apoio Domiciliário: "São as meninas que colocam (medicação) em cima da mesa neste prato. Nós andamos tratados por elas, são elas que nos tratam." (Entrevista … 12).

Estes cuidadores familiares idosos são os únicos responsáveis pela articulação entre os idosos dependentes e os médicos e enfermeiros.

Os vizinhos surgem como mais um apoio para estes cuidadores, auxiliando-os nas tarefas instrumentais mais pesadas, na tarefa de supervisão e nas situações de crise: "Temos muitos amigos e vizinhos que vêm cá ajudar.";"E esta vizinha da frente é que vinha aqui para eu colocar na casa de banho e vinham aqui todas as noites ajudar a deitar, porque eu sozinho não podia." (Entrevista n.. 8); "Sim, são elas (vizinhas) que me valem à noite." (Entrevista n. ${ }^{12}$ ).

Os vizinhos assumem um papel semelhante ao da família que não coabita com o cuidador, ou seja, prestam apoio aos cuidadores familiares idosos, de forma gratuita, auxiliando-os nas suas dificuldades e necessidades quotidianas.

Frequentemente, o apoio dos vizinhos ocorre no período em que o Serviço de Apoio Domiciliário não funciona (final da tarde e à noite). Os vizinhos asseguram as tarefas que os Serviços de Apoio Domiciliário tradicional não realizam, nomeadamente, a supervisão do idoso dependente com o objectivo de libertar o cuidador familiar idoso para a execução de actividades e compromissos pessoais e ligados à actividade de cuidar do idoso dependente (consultas médicas, compras, etc.).

51 As principais necessidades dos cuidadores familiares idosos da Solução B são as seguintes:

- Necessidades emocionais: "O que eu sinto falta é de sair, eu dantes às duas horas ia sempre com uma amiga tomar café e isso já era um lento para o resto do dia." (Entrevista n. ${ }^{2}$ ); "Eu não tenho ninguém, necessito de uma ajuda para a noite, estou sozinha!" (Entrevista n.․ 12).

- Necessidades materiais: "Ter o apoio à noite e uma companhia a meu lado..."; “... mas não pode ser (ter apoio à noite e companhia a meu lado) porque eu sou pobre.” (Entrevista n. ${ }^{\circ}$ 12).

52 Os cuidadores idosos da Solução B, ou seja, os cuidadores sem retaguarda familiar sentem necessidades idênticas às dos cuidadores da solução A que não coabitam com os filhos (solução A2). Eles expressam necessidades materiais e emocionais muito semelhantes. 
Referem necessidades a nível económico, necessidades de mais apoios técnicos e de serviços, necessidades pessoais e sociais, necessidade de uma companhia permanente.

Estes dois grupos de cuidadores executam mais tarefas que os cuidadores que coabitam com os filhos, estando por isso mais expostos a sobrecargas físicas e psicológicas. Executam uma gestão dos cuidados isolada e frágil, colocando em risco a sua própria saúde e a saúde do idoso dependente.

De referir que os cuidadores com retaguarda familiar mas que não coabitam com os filhos e os cuidadores sem retaguarda familiar se distinguem pelo facto de os primeiros possuírem ajudas pontuais dos filhos e repartirem com eles o estabelecimento de contactos com os médicos e enfermeiros, enquanto os cuidadores do segundo tipo têm ajudas pontuais dos vizinhos e gerem de forma autónoma os contactos com o pessoal de saúde.

\section{As respostas sociais e os novos desafios das situações de dependência na velhice}

Enquanto entidade financiadora e reguladora, o Estado tem apostado no crescente investimento nos serviços sociais para idosos. O Serviço de Apoio Domiciliário que registou a maior taxa de crescimento de todas as valências (Carta Social 2002) “... quer a nível de capacidade, quer a nível do número de utentes, (...) privilegiando esta resposta, em alternativa às convencionais respostas de institucionalização" (Martin, Gonçalves, Silva, Paúl e Cabral 2007), é o serviço de prestação de cuidados que, actualmente, maior apoio presta aos cuidadores familiares idosos e aos idosos dependentes que não pretendem abandonar o seu lar. No entanto, revela-se insuficiente na resolução dos problemas destes utentes.

$\mathrm{Na}$ área geográfica do nosso estudo, o Apoio Domiciliário constitui a única res- posta social implementada do conjunto das respostas sociais existentes (Serviço de Apoio Domiciliário, Apoio Domiciliário Integrado (ADI) e Unidade de Apoio Integrado), quando seria desejável pôr em prática todas as respostas sociais previstas pela Segurança Social com o objectivo de colmatar as necessidades dos idosos dependentes e dos seus cuidadores familiares idosos.

Os idosos dependentes não usufruem de cuidados permanentes e adequados às suas patologias e necessidades, uma vez que o Serviço de Apoio Domiciliário não possui uma equipa multidisciplinar nem um horário de funcionamento capaz de responder às carências dos seus utentes. O Serviço de Apoio Domiciliário não responde às necessidades físicas, psicológicas e sociais dos idosos dependentes e dos seus cuidadores familiares. Por outro lado, este serviço não deverá ser meramente assistencial sob pena de não ter uma função preventiva e reabilitadora. Na nossa opinião, seria desejável implementar um Serviço de Apoio Domiciliário flexível em termos de horário, com uma equipa multidisciplinar capaz de avaliar correctamente as necessidades dos idosos dependentes e dos cuidadores familiares e de lhes dar resposta.

Para os idosos mais dependentes são necessárias Unidades de Apoio Integrado e Unidades de Cuidados Continuados Domiciliares que possam apoiar as famílias que optam por cuidar dos seus idosos no domicílio. Estas respostas deverão ser partilhadas com o Centro de Saúde e as Instituições Particulares de Solidariedade Social e, na nossa perspectiva, 
baseadas em acordos diferenciados capazes de criar mais justiça social no acesso aos recursos.

59 A falta de apoio aos cuidadores é uma grave lacuna da política social do Estado. Para Kraan et al. (1993, citado por Osório e Pinto 2007), “... na prática, as políticas sociais destinam poucos recursos a aliviar a carga que suportam os cuidadores informais, quando de facto o problema da sobrecarga dos cuidadores informais é um problema político bastante significativo". Nesta pesquisa, verificamos que os cuidadores familiares idosos se apoiam sobretudo nos filhos (no caso da Solução A), nos vizinhos (na Solução B) e ainda nas empregadas sempre que os recursos económicos o permitem. Os filhos assumem tarefas relacionadas com o cuidar (supervisão, higiene e conforto, alimentação, articulação com médicos e enfermeiros, etc.) enquanto as empregadas e os vizinhos apenas executam tarefas pontuais de carácter instrumental (fazer companhia ao idoso dependente na ausência do cuidador familiar idoso, ajudar o cuidador familiar idoso na muda das fraldas e nos posicionamentos). O Serviço de Apoio Domiciliário não está preparado para apoiar os cuidadores familiares idosos, não possuindo por isso serviços direccionados para estes utentes. Esta lacuna das respostas sociais é particular- mente grave no caso dos cuidadores da solução $B$, que, não tendo retaguarda familiar, não têm com quem partilhar a sobrecarga física e psicológica inerente à gestão dos cuidados.

Não existindo um apoio direccionado para os cuidadores familiares, em geral, e os cuidadores familiares idosos, em particular, impõe-se inserir os cuidadores nas respostas sociais, criando novos serviços que não descurem as suas necessidades em termos físicos, psicológicos e sociais. Entre outros aspectos, as políticas sociais dirigidas aos cuidadores deveriam contemplar a sua formação e acompanhamento e potenciar o seu suporte social através, nomeadamente, do voluntariado de proximidade.

61 Arca (2007) refere que “... a prestação de cuidados aos nossos idosos deve constituir uma responsabilidade partilhada entre obrigação moral e ética da família e a obrigação social do Estado enquanto garante dos direitos fundamentais de todo e qualquer cidadão, independentemente da sua idade." Neste sentido, o autor defende que o Estado deveria valorizar as "... mudanças actualmente em curso no seio da estrutura familiar" que afectaram claramente a “... capacidade da família para desempenhar o seu papel tradicional como única e imprescindível prestadora de cuidados".

Apesar de dispormos de políticas sociais para os idosos, bastante abrangentes e inovadoras, verificamos que não atingem uma grande parte da população-alvo por falta de divulgação e de capacidade económica dos idosos portugueses.

Os cuidadores familiares idosos que entrevistamos usufruíam apenas do Serviço de Apoio Domiciliário (que não cobria a maior parte das suas necessidades) e conheciam uma das mais recentes medidas de apoio do Estado, o "Complemento Solidário para Idosos", mas alguns indivíduos confundiam esta última medida com o "Complemento por Dependência". Esta falta de informação gera passividade nos idosos e nas suas famílias que, desconhecendo os seus direitos, não os reivindicam. No entanto, a análise das medidas políticas existentes sugere que o Estado está atento às necessidades da população idosa. Urge pois apostar na divulgação mais agressiva das respostas sociais existentes, capaz de chegar aos idosos e famílias mais carenciadas e com um nível de escolaridade baixo.

Neste trabalho, verificamos ainda não haver articulação entre os Centros de Saúde e os Serviços de Apoio Domiciliário. Por outro lado, constatámos existirem dificuldades por 
parte dos Centros de Saúde em responder de forma adequada às necessidades dos cuidadores e idosos dependentes. Os Centros de Saúde limitam-se, quase sempre, a satisfazer as solicitações dos idosos que a eles se dirigem, o que não assegura a continuidade dos cuidados e a prevenção da doença. Seria desejável que os Centros de Saúde apoiassem mais os idosos dependentes e os seus cuidadores idosos em contexto domiciliar. Esta situação encontra-se prevista no Apoio Domiciliário Integrado. No entanto, este tipo de resposta ainda é privilégio de uma minoria.

Verificamos neste estudo que, sempre que existe retaguarda familiar, os filhos apoiam os cuidadores idosos, sempre que é necessário marcar consultas, ir ao médico ou recorrer a tratamentos de enfermagem. Quando não existe apoio por parte da família, esta tarefa cabe exclusivamente aos cuidadores familiares idosos que a assumem de forma inequívoca, apesar da sobrecarga psicológica que acarreta, por considerarem ser sua obrigação moral. Estes resultados sugerem que seja repensada a falta de articulação existente entre os serviços de saúde e as respostas sociais para idosos.

Os cuidadores familiares idosos são responsáveis pela administração da medicação, tanto na solução A como na solução B. Esta realidade comporta riscos bastante elevados, uma vez que, frequentemente, estes cuidadores possuem debilidades físicas, cognitivas e psicológicas que podem comprometer a correcta administração dos medicamentos. A polimedicação, a automedicação e a incorrecta administração dos medicamentos constituem um dos pontos mais críticos da gestão dos cuidados a cargo dos cuidadores idosos. Na ausência de apoio da família, a administração da medicação deveria ser realizada por pessoal técnico do Serviço de Apoio Domiciliário. Esta tarefa poderia ser assegurada se o horário de funcionamento deste serviço fosse alargado.

Finalmente, os níveis de pobreza da população idosa portuguesa limitam o seu acesso a serviços que poderiam aliviar a sobrecarga física e psicológica dos cuidadores. Com efeito, tendo em conta o limiar de pobreza estimado pelo EUROSTAT para Portugal, a pobreza monetária atingia 35,4\% dos idosos residentes na região Norte do país, em 2001-2002 (Delerue Matos 2007: 256). Os idosos que vivem sós e os casais de idosos assim como os indivíduos com uma saúde precária constituem alguns dos grupos mais vulneráveis em termos de pobreza monetária e pobreza segundo as condições de vida (Delerue Matos 2008). Os cuidadores familiares idosos e os idosos dependentes que pertencem a estes grupos não estão em condições de adquirir novos serviços de Apoio Domiciliário nem de contratarem uma empregada doméstica. 0 reforço de subsídios como o "Complemento Solidário para Idosos" ou a gratuidade de serviços considerados indispensáveis aos idosos dependentes e aos seus cuidadores, de acordo com uma avaliação criteriosa das necessidades e dos recursos económicos dos mesmos, permitiria melhorar a qualidade de vida destes idosos ao mesmo tempo que introduziria uma maior justiça social. 


\section{BIBLIOGRAFIA}

ARCA, B. R. (2007), “Apoio familiar e institucional à pessoa idosa” (cap. X), in A. R. Osório, F. C. Pinto (coord.) (2007), As Pessoas Idosas. Contexto social e intervenção educativa, Lisboa: Instituto Piaget.

BENHAMOU, R. (s.d.), Avaliar a Dependência dos Idosos. Proposta de uma escala de avaliação rápida e global, Lisboa, Direcção-Geral de Saúde.

DELERUE MATOS, A. (2008), “A velhice em contexto de pobreza: isolamento ou integração familiar e social?”, in M. E. Leandro (org.), Laços Familiares e Sociais, Braga, PsicoSoma (no prelo).

DELERUE MATOS, A. (2007), Cohabitation, "intimité à distance" ou isolement familial ? Les rapports familiaux intergénérationnels aux âges élevés dans la société portugaise, thèse présentée en vue de l'obtention du titre de Docteur en Sciences Sociales (Démographie), Louvain-la-Neuve: Université Catholique de Louvain-la-Neuve: $321 \mathrm{pp}$.

INE (2002), O Envelhecimento em Portugal: Situação demográfica e socioeconómica recente das pessoas idosas, Lisboa: Departamento de Estatística Censitárias e da População.

LESEMANN, F., MARTIN, C. (org.) (1993), Les Personnes âgées. Dépendence, soins et solidarités familiales: comparaisons internationales, Paris, La Documentation Française.

MARTIN, I., GONÇALVES, D., SILVA, A., PAÚL, C., CABRAL, F. P. (2007), “Políticas sociais para a Terceira Idade” (cap. XI), in A. R. Osório, F. C. Pinto (coord.) (2007), As Pessoas Idosas. Contexto social e intervenção educativa, Lisboa: Instituto Piaget.

MINUCHIN, S., FISHMAN, H. C. (1990), Técnicas de Terapia Familiar, Porto Alegre: Artes Médicas.

OSÓRIO, A. Requejo, PINTO, F. Cabral (2007), As Pessoas Idosas. Contexto social e intervenção educativa, Lisboa: Horizontes Pedagógicos.

PAÚL, M. Constança (1997), Lá para o Fim da Vida. Idosos, familia e meio ambiente, Coimbra: Almedina.

QUARESMA, Maria L., FERNANDES, Ana A., CALADO, D. Ferreira, PEREIRA, Micael (2004), o Sentido das Idades da Vida - Interrogar a solidão e a dependência, Lisboa: CESDET.

SEQUEIRA, C. (2007), Cuidar de Idosos Dependentes, Coimbra: Quarteto.

VIEIRA, E. B. (1996), Manual de Gerontologia: Um guia prático para profissionais, cuidadores e familiares, Rio de Janeiro: Revinter.

\section{NOTAS}

1. Segundo o último recenseamento da população, os idosos representam $16,4 \%$ da população total (INE 2002). 32,3\% das famílias contam com pelo menos um idoso. Do conjunto de famílias com um único elemento, 50,8\% são constituídas por um indivíduo de 65 anos ou mais e, do conjunto de famílias com dois elementos, $42 \%$ são famílias de idosos. 


\section{RESUMOS}

Neste trabalho, analisamos a gestão dos cuidados a idosos dependentes que se encontram em contexto domiciliar, a cargo de cuidadores familiares idosos. Visamos identificar e explicar as diferentes formas de gestão dos cuidados, pondo em evidência os riscos inerentes a cada uma delas. Esta análise remete-nos para a avaliação das políticas sociais para os idosos e leva-nos a propor medidas específicas de apoio aos cuidadores familiares idosos.

A pesquisa assenta no resultado da aplicação de entrevistas semi-estruturadas a dezassete cuidadores familiares idosos com idosos dependentes a cargo, que usufruem do Serviço de Apoio Domiciliário no concelho de Barcelos.

This article analyses care management practices provided by elderly family members to dependent relatives in their households.

The authors attempt at identifying and explaining the diverse ways of managing that care, pointing out their inherent risks. From here an evaluation of the social policies for the aged is put forward followed by a suggestion of specific guidelines to support elderly caregivers.

The research is based on 17 semi-structured interviews of elderly caregivers that assist dependent relatives and are users of the 'domestic care services' (SAD) in Barcelos.

Dans cette recherche, nous analysons la gestion des soins aux personnes âgées dépendantes assurés par des individus âgés de la parenté.

Nous nous proposons d'identifier et d'expliquer les différents types de gestion des soins et leurs risques. Ceci nous emmène à évaluer les politiques sociales dirigées aux personnes âgées et à proposer des mesures de support aux aidants âgés.

Cette recherche s'appuie sur le résultat d'entretiens semi-structurés à 17 aidants familiaux âgés avec des personnes âgées dépendantes à charge qui reçoivent, également, le soutien des Services d'Aide à Domicile de Barcelos.

\section{ÍNDICE}

Palavras-chave: idosos, cuidados a idosos, cuidadores familiares, políticas sociais

\section{AUTORES}

\section{FÁTIMA BARBOSA}

Lar Santo André, Santa Casa da Misericórdia de Barcelos

fatimacristinasenra@sapo.pt

\section{ALICE DELERUE MATOS}

Departamento de Sociologia, Instituto de Ciências Sociais, Universidade do Minho adelerue@ics.uminho.pt 